\title{
Polimorfismos das Isoformas M1, T1 e P1 da Glutationa $S$-transferase e Associação com os Aspectos Clínico-Patológicas no Carcinoma Colorretal
}

\author{
Polymorphism of Glutathione $S$-transferase M1, T1 and P1 and Association with \\ Clinicopathological Aspects in Colorectal Carcinoma
}

\author{
POLIANAL.ANSOLIN ${ }^{1}$, DANIEL C. DAMIN ${ }^{3}$, CLÁUDIO O.P.ALEXANDRE ${ }^{1,2}$ \\ ${ }^{1}$ Laboratório de Biologia Molecular da Pós-graduação, Universidade Federal de Ciências da Saúde de Porto Alegre \\ (UFCSPA); ${ }^{2}$ Departamento de Ciências Básicas da Saúde, Universidade Federal de Ciências da Saúde de Porto Alegre \\ UFCSPA. Porto Alegre, 90050-170, RS, Brasil. Email: calex@ufcspa.edu.br; ${ }^{3}$ Divisão de Coloproctologia , \\ Departamento de Cirurgia, Hospital de Clínicas, Universidade Federal do Rio Grande do Sul, Porto Alegre, RS, Brasil.
}

\begin{abstract}
ANSOLIN PL; DAMIN DC; ALEXANDRE COP. Polimorfismos das Isoformas M1, T1 e P1 da Glutationa $S$-Transferase e Associação com os Aspectos Clínico-Patológicas no Carcinoma Colorretal. Rev bras Coloproct, 2010;30(3): 281-288.

RESUMO: As variáveis clínico-patológicas são importantes fatores que possam estar associados à progressão da neoplasia e, conseqüentemente, ao prognóstico da doença. As glutationas S-Transferases GSTM1, GSTT1 e GSTP1 são enzimas da segunda fase de biotransformação que atuam na destoxificação de uma ampla variedade de agentes exógenos incluindo os carcinógenos. Os genes GSTM1 GSTT1 e GSTP1 são polimórficos em humanos e suas variantes têm sido associadas, em algumas populações, ao aumento dos riscos de neoplasia, entre elas o carcinoma colorretal. Neste estudo retrospectivo 50 biópsias de pacientes com carcinoma colorretal do Rio Grande do Sul foram analisadas os polimorfismos nos genes GSTM1 GSTT1 e GSTP1 por PCR multiplex e RFLP, quanto às variáveis clínico-patológicas: localização, estadiamento e diferenciação. Não foram encontrados valores $p$ significativo nas variáveis: estadiamento $(p=0,28, p=0,93$ e p=0,67), diferenciação $(p=0,70$ e $p=0,37)$ e localização $(p=$ 0,23. $p=0,58$ e $p=0,60$ ) respectivamente e o presença do polimorfismos dos genes GSTM1, GSTT1 e GSTP1 nas variáveis estadiamento e localização. A única variável clínico-patológica que apresentou valor significativo na diferenciação do CCR foi o polimorfismo do gene GSTP1 Ile/val e val/val ( $p=0,046)$ entretanto, mais pesquisas são necessárias para confirmar estes achados ,visto que, esses resultados podem ter sido influenciados pelo número reduzido de biópsias analisadas.
\end{abstract}

Descritores: GSTs, Câncer colorretal, Aspectos clínico-patológicos.

\section{INTRODUÇÃO}

Os tumores malignos que acometem o cólon e o reto representam o segundo tipo de neoplasia mais prevalente no mundo, após o câncer de mama, com uma estimativa de 2,4 milhões de casos nos últimos cinco anos, ou seja, a cada ano estimam-se em 945 mil casos novos ${ }^{6}$. As estimativas para câncer colorretal (CCR) no ano de 2008 para o Brasil foi de 12.490 casos em homens e de 14.500 em mulheres
${ }^{21}$. Estes valores correspondem a um risco estimado de 13 novos casos a cada 100 mil homens e 15 para cada 100 mil mulheres. Em relação à mortalidade, no Brasil, este tipo de neoplasia situa-se na quinta posição entre as causas de óbitos mais frequentes para ambos os sexos ${ }^{31}$.

A variabilidade dos comportamentos clínico e biológico do CCR tem suscitado grande interesse pelo estudo de fatores que possam estar associados à progressão da neoplasia e, conseqüentemente, ao prog-

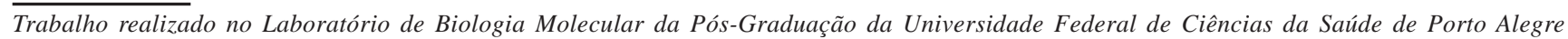
- UFCSPA, correspondente ao Departamento de Ciências Básicas da Saúde. 
nóstico da doença ${ }^{26,37}$. O diagnóstico precoce ${ }^{38}$ a idade ${ }^{7}$ localização da neoplasia ${ }^{44}$, graduação histológica ${ }^{15}$,grau de penetração na parede intestinal ${ }^{11}$, comprometimento linfonodal ${ }^{2}$ produção de muco pela neoplasia ${ }^{16}$ antígeno carcinoembrinonário (CEA) ${ }^{25}$, invasão venosa e neuronal ${ }^{22}$ são as variáveis mais frequentemente estudadas, como fatores relacionados ao prognóstico do CCR. Estudos foram realizados com o intuito de discriminar o poder prognóstico independente das principais variáveis relacionadas ao $\mathrm{CCR}^{23}$ ${ }^{35}$. Os resultados revelaram que os fatores que apresentam associação com a evolução dos doentes são: profundidade de infiltração do tumor na parede intestinal, o comprometimento linfonodal, a presença de metástases e a graduação histológica da neoplasia ${ }^{23,35}$.

O estadiamento patológico é utilizado para avaliar o prognóstico e determinar o tratamento de pacientes com câncer colorretal. O estadiamento de Dukes ainda é comumente utilizado embora essa classificação foi inicialmente limitado a três classes (A, B e C): O estadiamento A corresponde a carcinoma limitado á parede intestinal, o estadiamento B a propagação do local de carcinoma além da parede do intestino sem envolvimento nos nódulos e o estadiamento $\mathrm{C}$ acometimento linfonodal com a divisão em $\mathrm{C}$ 1: nódulo local e C2: nódulo apical, Dukes classe D foi posteriormente adicionado para indicar a presença de metástase distantes ${ }^{11,44}$. Foi demonstrado ${ }^{20}$ que o sistema TNM poderia ser facilmente adaptado a fim de corresponder ao Dukes. O sistema TNM da UICC (Universal Staging System for Cancer of the colon and rectum) para a classificação dos tumores malignos descreve a extensão anatômica da doença tem por base a avaliação de três componentes: a extensão do tumor primário $\mathrm{T}$, a ausência ou presença e a extensão de metástase em linfonodos regionais $\mathrm{N} \mathrm{e}$ ausência ou presença de metástase à distância $\mathrm{M}$. Esse sistema segue simples considerações fisiopatológicas eliminando ambigüidades e confusão devidas ás inúmeras revisões do procedimento dos Duques ${ }^{40,8}$. Assim, o estadiamento I (Dukes A) o tumor invadi a submucosa (T1) ou a parede muscular (T2). No estadiamento II (Dukes B) lesões invadem através da musculatura própria na subserosa e tecidos pericólica (T3) ou se infiltra no peritônio visceral invadindo outros órgãos (T4), No estadiamento III há um comprometimento metastático nos nódulos linfáticos (N1 1 a 3 nódulos e N2 mas do que 3 nódulos) e finalmente o estadiamento IV (Dukes D).
Outra variável clínico-patológica que também será estudada neste artigo é a gradação histopatológica refere-se a informações posteriores, relativas ao tumor primário podem ser registrado sob os seguintes títulos: Grau de diferenciação não pode ser avaliado, bem diferenciado, moderadamente diferenciado, pouco diferenciado e indiferenciado ${ }^{6,5}$.

Vários genes polimórficos que codificam enzimas envolvidas na biotransformação de carcinógenos têm sido associados ao desenvolvimento do câncer ${ }^{24}$. Três genes em particular, GSTM1, GSTT1 e GSTP1 que codificam enzimas da fase II pertencentes à família da glutationa S-transferase (GSTs), parecem relevantes para a suscetibilidade ao câncer 28, 32, 34 e 42, pois atuam na destoxificação de metabólitos reativos de substâncias carcinogênicas presentes no ambiente. Os genes, GSTM1, GSTT1 e GSTP1 são polimórficos na população humana ${ }^{3}$. Indivíduos portadores da deleção do alelo GSTM1 e/ou do GSTT1 em homozigose podem apresentar suscetibilidade para desenvolver alguns tipos de neoplasias, principalmente os tumores etiologicamente relacionados aos modos e hábito de vida devido à redução nos processos de detoxificação ${ }^{13} \mathrm{O}$ polimorfismo de um único nucleotídeo (SNP) do gene GSTP1 é caracterizado pela transição de adenina (A) para guanina $(\mathrm{G})$, resultando a substituição (codon 105, Isoleucine '! Valine). Essa substituição não-sinônima resulta em uma alteração da atividade catalítica do produto do gene GSTP1. Devido ao fato, da mudança do aminoácido ${ }^{1}$ ocorrer perto do sítio de ligação hidrofóbico de eletrófilos tanto o genótipo homozigoto (GSTP1 Ile/Ile) e heterozigoto (GSTPI Ile/Val) podem resultar em uma diminuição específica da atividade e afinidade por compostos eletrofílico, podendo ser um fator de risco para o desenvolvimento de neoplasias ${ }^{18,41}$

Este estudo retrospectivo procurou correlacionar algumas das variáveis clinico- patológicas entre elas: localização; reto, colón esquerdo (descendente, sigmóide tranverso distal), colón direito (ceco, ascendente e tranverso proximal); estadiamento: tumor até mucosa e musculatura própria, tumor até serosa ou gordura perirretal e, metástase nos linfonodos e metástase a distância e a gradação histopatológica: bem diferenciado, moderadamente diferenciado e pouco diferenciado com os polimorfismos dos genes GSTM1, GSTT1 e GSTP1 em pacientes com carcinoma colorretal. 


\section{MÉTODOS}

Foram avaliadas retrospectivamente 50 biópsias de pacientes com carcinoma colorretal quanto às variáveis clínico-patológicas: localização, estadiamento e diferenciação obtidas no período de 2003 a 2005 junto ao Serviço de Coloproctologia do Hospital de Clínicas de Porto Alegre (HCPA), sendo que dessas, 43,3\% eram pertencentes do sexo masculino com média de idade entre $(65,2 \pm 13,2$ anos). Somente foram incluídas as biópsias com diagnóstico confirmado de carcinoma colorretal por meio da análise anatomopatológica. Após a coleta, as amostras foram armazenadas em formalina $10 \%$ e, logo após, congeladas à $-20^{\circ} \mathrm{C}$. Esse projeto foi aprovado pelo Comitê de Ética em Pesquisa da UFCSPA (CEP-UFCSPA) e todos os pacientes envolvidos assinaram o Termo de Consentimento Livre e Esclarecido (TCLE).

O DNA genômico foi extraído dos tecidos utilizando o kit de extração "PureLink TM Genomic DNA Mini Kit" (Invitrogen ${ }^{\circledR}$ ) de acordo com o procedimento descrito pelo fabricante (Manual Kit Invitrogen). O DNA genômico das amostras foi amplificado utilizando-se primers específicos para os genes GSTMI (5', GAA CTC CCT GAA AAG CTA AAG C 3' e 5' GTT GGG CTC AAATAT ACG GTG G3') ${ }^{4} G S T T 1$ (5'TTC CTT ACT GGT CCT CAC ATC TC 3' e 5'TCA CCG GAT CAT GGC CAG CA 3') ${ }^{33}$ e GSTP1 (5' ACC CCA GGG CTC TAT GGG AA 3' e 5'TGA GGG CAC AAG AAG CCC CT 3' ) ${ }^{17}$. A análise dos genes GSTM1 e GSTT1 foram realizadas simultaneamente pela reação multiplex em cadeia da polimerase (PCR) ${ }^{14} \mathrm{com}$ algumas modificações. Cada reação consistiu em uma mistura contendo 100ng de DNA, 5uL de 10 x Tampão de PCR ( 10 x 500mM KCl, 100 mM Tris-HCl, pH 9.0), $15 \mathrm{pmol}$ de cada um dos primers específicos, $0,3 \mathrm{mM}$ dNTPs e 1U de Platinum Taq DNA Polymerase High Fidelity (Invitrogen ${ }^{\circledR}$ ) em um volume total de $50 \mu \mathrm{L}$. A análise do polimorfismo do gene GSTP1 foi feita pela técnica PCR-RFLP ${ }^{17}$. Os produtos de amplificação foram analisados em gel de agarose $3 \%$ corado com brometo de etídeo $(10 \mathrm{mg} / \mathrm{ml})$ e visualizados sob luz ultravioleta. A presença ou a ausência dos genes GSTMI e GSTT1 foi detectada pela presença ou ausência de uma banda de $215 \mathrm{pb}$ e uma banda $480 \mathrm{pb}$ respectivamente. O gene GSTP1 serviu como controle interno de amplificação, apresentando uma banda de $176 \mathrm{pb}$, visto que o tipo de polimorfismo em ambos os genes analisados (GSTM1 e GSTT1) é do tipo deleção.
Para as análises estatísticas das variáveis clínico-patológicas e sua associação com o polimorfismo dos genes GSTM1, GSTT1 e GSTP1, utilizou-se o teste Qui-quadrado de Pearson, com nível de significância de 5\%. Os dados foram analisados com auxílio dos programas SPSS (Statistical Package for the Social Sciences Program for Windows-versão 13).

\section{RESULTADOS}

A variável clínico patológica localização não apresentou valores estatisticamente significativo $(\mathrm{p}=0,23 \cdot \mathrm{p}=0,58 \mathrm{e} \mathrm{p}=0,60)$ na presença do polimorfismo dos genes GSTM1, GSTT1 e GSTP1 respectivamente. Com relação à localização no reto: $32 \%$ e $24 \%$, cólon esquerdo: $50 \%$ e $35,7 \%$, cólon direito: 18,2\% e 18,2\% apresentaram deleção do gene GSTM1, GSTT1 respectivamente (tabela 1 e 2 ). No gene GSTP1 $44 \%$ e $8 \%$ no reto $35,7 \%$ e $7,1 \%$ no cólon esquerdo e $18,2 \%$ e $18,2 \%$ no cólon direito apresentaram o polimorfismo GSTP1 ile/val e val/val respectivamente ( tabela 3). Não foram observadas diferenças estatística $(\mathrm{p}=0,33)$ no genótipo GSTM1 null /GSTT1 null e na combinação dos genótipos GSTM1 null / GSTT1 null / GSTP1 ile/val e val/val ( $\mathrm{p}=0,13)$ quanto a localização do CCR.

Com relação ao estadiamento do CCR também não foram encontrados valores estatisticamente significativo ( $\mathrm{p}=0,28, \mathrm{p}=0,93 \mathrm{e} \mathrm{p}=0,67)$ na presença do polimorfismo dos genes GSTM1, GSTT1 e GSTP1 respectivamente. $\mathrm{O}$ estadiamento do tumor até a mucosa e musculatura própria foi de $50 \%$ e $16,7 \%$; $47,1 \%$ e $29,4 \%$ no estadiamento do tumor até a serosa e gordura perirretal; $20 \%$ e $25 \%$ metástase nos linfonodos e 28,6\% e 28,6\% metástase á distância apresentaram deleção do gene GSTM1, GSTT1 respectivamente (tabela 1 e 2). No gene GSTP1 50\% e 16,7\% apresentaram estadiamento do tumor até a mucosa e musculatura própria, 29,4\% e 5,9\% tumor até a serosa ou gordura perirretal, $40 \%$ e $15 \%$ metástase nos linfonodos e $28,6 \%$ e $0 \%$ metástase á distância o polimorfismo GSTP1 ile/val GSTP1 val/val respectivamente (tabela 3). Quando foi feita a combinação dos genótipos GSTM1 null /GSTT1 null e GSTM1 null/ GSTT1 null / GSTP1 ile/val e/ou val/val com o estadiamento do CCR também não foram encontrados valores estatisticamente significativos $(p=0,85$ e $p=0,72)$ respectivamente. 
Tabela 1 - Associação com as variáveis clínico-patológicas e a presença da deleção do gene GSTM1.

\begin{tabular}{lrrrr}
\hline Características Clínicas(n) & \multicolumn{3}{c}{ Polimorfismo GSTM $_{\mathbf{1}}(\boldsymbol{\%})$} & $\mathbf{p}$ \\
\hline Diferenciação & $(1)$ & 0 & $(0)$ & \\
Bem diferenciado & $(45)$ & 16 & $(35,6)$ & 0,70 \\
Moderadamente diferenciado & $(4)$ & 1 & $(25,0)$ & \\
Pouco diferenciado & & & & \\
Estadiamento & $(6)$ & 3 & $(50,0)$ & \\
Tumor até mucosa e musculatura própria & $(17)$ & 8 & $(47,1)$ & 0,28 \\
Tumor até serosa ou gordura perirretal & $(20)$ & 4 & $(20)$ & \\
Metástase nos linfonodos & $(7)$ & 2 & $(28,6)$ & \\
Metástase à distância & & & & \\
Localização & $(25)$ & 8 & $(32,0)$ & \\
Reto & $(11)$ & 2 & $(18,2)$ & \\
Cólon direito & $(14)$ & 7 & $(50,0)$ & \\
Cólon esquerdo & & &
\end{tabular}

Tabela 2 - Associação com as variáveis clínico-patológicas e a presença da deleção do gene GSTT1.

\begin{tabular}{|c|c|c|c|}
\hline Características Clínicas(n) & & ${\text { Polimorfismo } \text { GSTM }_{1}(\%)}$ & $\mathbf{p}$ \\
\hline \multicolumn{4}{|l|}{ Diferenciação } \\
\hline Bem diferenciado & (1) & $(0)$ & \\
\hline Moderadamente diferenciado & $(45)$ & $13 \quad(28,9)$ & 0,37 \\
\hline Pouco diferenciado & (4) & $(0)$ & \\
\hline \multicolumn{4}{|l|}{ Estadiamento } \\
\hline Tumor até mucosa e musculatura própria & (6) & $1 \quad(16,7)$ & \\
\hline Tumor até serosa ou gordura perirretal & $(17)$ & $5 \quad(29,4)$ & 0,93 \\
\hline Metástase nos linfonodos & $(20)$ & $5 \quad(25)$ & \\
\hline Metástase à distância & (7) & $2(28,6)$ & \\
\hline \multicolumn{4}{|l|}{ Localização } \\
\hline Reto & $(25)$ & $6 \quad(24,0)$ & \\
\hline Cólon direito & (11) & $2 \quad(18,2)$ & 0,58 \\
\hline Cólon esquerdo & (14) & $5 \quad(35,7)$ & \\
\hline
\end{tabular}

A única variável clínico-patológica que apresentou valor significativo na diferenciação do CCR foi o polimorfismo do gene GSTP1 Ile/val e val/val ( $\mathrm{p}=$ 0,046) (tabela 3). O polimorfismo dos outros genes GSTM1 e GSTT1 quando correlacionado com a diferenciação do CCR, não apresentaram valores estatisticamente significativo ( $\mathrm{p}=0,70$ e $\mathrm{p}=0,37)$ respectivamente (tabela 1 e 2). Quando foi feita a combinação dos genótipos GSTM1 null /GSTT1 null e GSTM1 null/ GSTT1 null / GSTP1 ile/val e/ou val/val com a diferenciação do CCR também não foram encontrados valores estatisticamente significativos $(p=0,87$ e $\mathrm{p}=0,11$ ) respectivamente.

\section{DISCUSSÃO}

Nossos resultados mostraram que as principais características clínico-patológicas não foram associadas com a presença do polimorfismo das principais isoformas da GSTs (GSTM1, GSTT1 e GSTP1) po- 
Tabela 3 - Associação com as variáveis clínico-patológicas e a presença do polimorfismo do gene GSTP1.

\begin{tabular}{|c|c|c|c|}
\hline \multicolumn{2}{|l|}{ Características Clínicas(n) } & Polimorfismo GSTM $1 \%$ ) & \multirow[t]{2}{*}{$\mathbf{p}$} \\
\hline Diferenciação & & & \\
\hline Bem diferenciado & (1) & & \\
\hline ile/ile & & $0 \quad(0)$ & \\
\hline ile/val & & $0 \quad(0)$ & \\
\hline $\mathrm{val} / \mathrm{val}$ & & 1 (100) & 0,046 \\
\hline Moderadamente diferenciado & $(45)$ & & \\
\hline ile/ile & & $25 \quad(55,6)$ & \\
\hline Ile/val & & $16 \quad(35,6)$ & \\
\hline $\mathrm{val} / \mathrm{val}$ & & $4 \quad(8,9)$ & \\
\hline Pouco diferenciado & (4) & & \\
\hline ile/ile & & $2 \quad(50)$ & \\
\hline Ile/val & & $2 \quad(50)$ & \\
\hline $\mathrm{val} / \mathrm{val}$ & & $0 \quad(0)$ & \\
\hline \multicolumn{4}{|l|}{ Estadiamento } \\
\hline Tumor até mucosa e musculatura própria & (6) & & 0,67 \\
\hline$x^{3}$ & & $2 \quad(33,3)$ & \\
\hline ile/val & & $3 \quad(50)$ & \\
\hline $\mathrm{val} / \mathrm{val}$ & & $1 \quad(16,7)$ & \\
\hline Tumor até serosa ou gordura perirretal & $(17)$ & & \\
\hline ile/ile & & $11 \quad(64,7)$ & \\
\hline ile/val & & $5 \quad(29,4)$ & \\
\hline $\mathrm{val} / \mathrm{val}$ & & $1 \quad(5,9)$ & \\
\hline Metástase nos linfonodos & $(20)$ & & \\
\hline ile/ile & & $9 \quad(45)$ & \\
\hline ile/val & & $8 \quad(40)$ & \\
\hline $\mathrm{val} / \mathrm{val}$ & & $3 \quad(15)$ & \\
\hline Metástase à distância & (7) & & \\
\hline ile/ile & & $5 \quad(71,4)$ & \\
\hline ile/val & & $2 \quad(28,6)$ & \\
\hline $\mathrm{val} / \mathrm{val}$ & & $0 \quad(0)$ & \\
\hline \multicolumn{4}{|l|}{ Localização } \\
\hline Reto & $(25)$ & & \\
\hline ile/ile & & $12 \quad(48)$ & \\
\hline ile/val & & $11 \quad(44,0)$ & 0,60 \\
\hline $\mathrm{val} / \mathrm{val}$ & & $2 \quad(8)$ & \\
\hline Cólon direito & (11) & & \\
\hline ile/ile & & $7 \quad(63,6)$ & \\
\hline ile/val & & $2 \quad(18,2)$ & \\
\hline $\mathrm{val} / \mathrm{val}$ & & $2 \quad(18,2)$ & \\
\hline Cólon esquerdo & (14) & & \\
\hline ile/ile & & $8 \quad(57,1)$ & \\
\hline ile/val & & $5 \quad(35,7)$ & \\
\hline $\mathrm{val} / \mathrm{val}$ & & $1 \quad(7,1)$ & \\
\hline
\end{tabular}




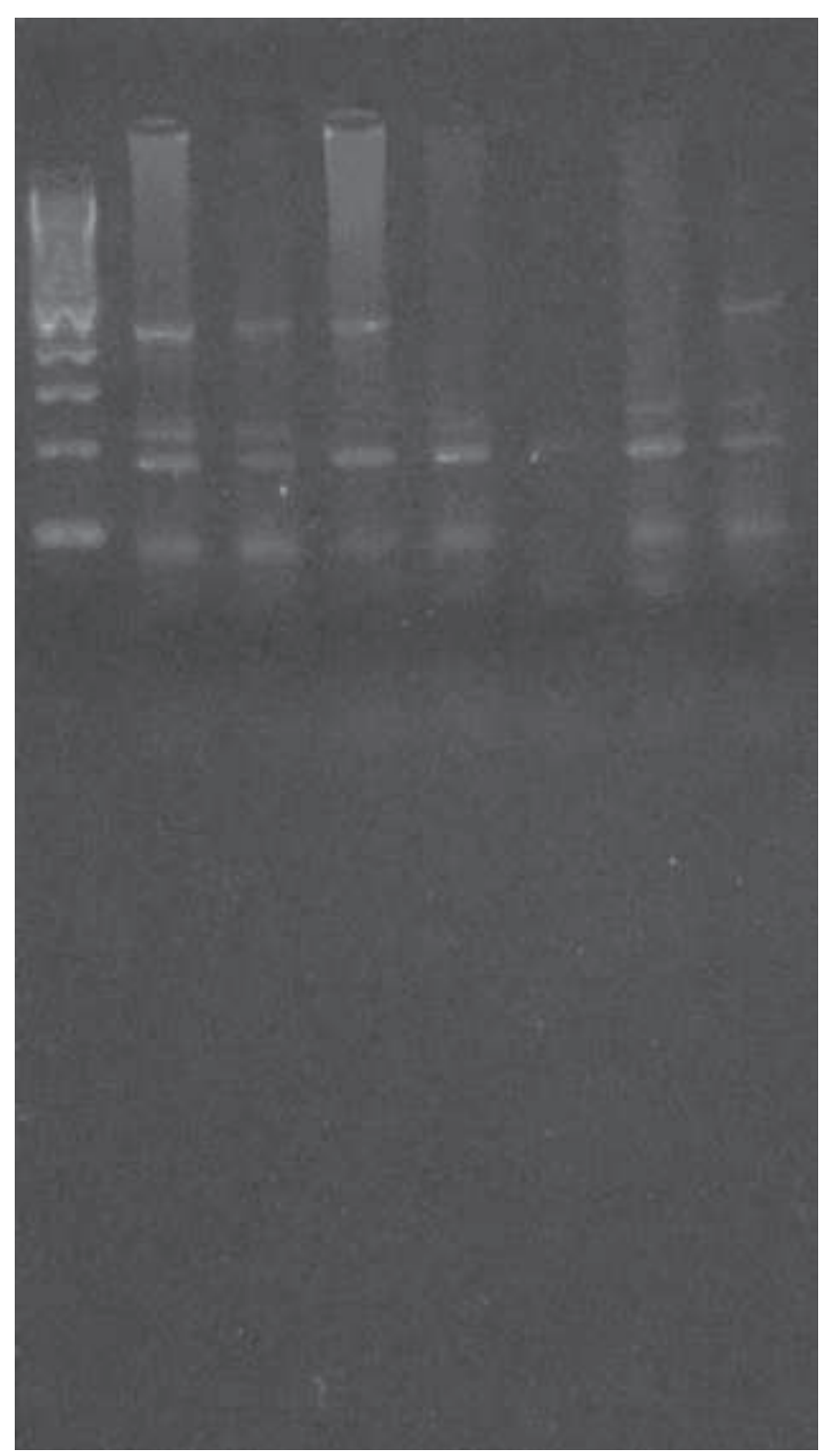

Figura 1 - PCR Multiplex analisado em gel de agarose 3\%. Canaleta1, marcador de peso molecular de 100pb; canaleta 2, 3 e 8, indivíduo sem deleção GSTM1 (+)/GSTT 1 (+); canaleta 4, indivíduo com deleção do GSTM1 null; canaleta 5 e 7, indivíduo com deleção GSTT, null canaleta 6, indivíduo com deleção GSTM1 null $/$ GSTT $_{1}$ null.

dendo sugerir que além dos polimorfismos herdado da GSTs, os indivíduos podem diferir na atividade da enzima por causa da exposição diferencial aos compostos bioativos ${ }^{9}$ assim, para análise do perfil das isoenzimas GSTs devemos levar em conta além do polimorfismo herdado destas isoenzimas a exposição a substancias carcinógenas presentes no ambiente o que torna os resultados inconsistentes visto que estudos epidemiológicos sugerem que até $80 \%$ dos cânceres humanos surgem como consequência da exposição ambiental ${ }^{10}$ principalmente os tumores etiologicamente relacionados aos modos e hábito de vida devido como o CCR.

A maioria das malignidades no CCR estão localizadas no cólon sigmóide e no reto (60-70\%) ${ }^{36}$. Neste trabalho podemos verificar que a maior parte dos indivíduos com CCR que apresentam polimorfismo em alguns destes genes, o tumor estava localizado no reto embora não foi encontrado valor significativo quanto à localização devemos considerar o pequeno número de biópsias analisadas. De acordo com alguns autores ${ }^{30,39}$ nos últimos anos tem-se visto um aumento na incidência do tumor no cólon proximal (cólon ascendente a transverso). No câncer hereditário colorretal, o tumor está preferencialmente localizado no cólon proximal ${ }^{29}$.

O prognóstico está intimamente relacionado com o estadiamento do tumor na apresentação e na técnica cirúrgica ${ }^{35,43}$. A única variável clínica que se mostrou significativa foi à diferenciação no gene GSTP1, entretanto em termos práticos a diferenciação do CCR possui pouco ou nenhum impacto clínico, pois não existem evidências suficientes de que está classificação possa afetar a sobrevivência ou servir como um guia para decidir o tipo de quimioterapia adjuvante ou radioterapia ${ }^{19}$.

\section{CONCLUSÃO}

Neste estudo não foi possível estabelecer uma associação entre as variáveis clinico-patológicas: estadiamento, localização e diferenciação no CCR com a deleção do gene GSTM1, GSTT1 e o polimorfismo GSTP1 nas variáveis estadiamento e localização separados e combinados A única variável que mostrou ser significativa foi a diferenciação do CCR na presença do polimorfismo do gene GSTP1 Ile/val e val/val entretanto, mais pesquisas são necessárias para confirmar estes achados, visto que, esses resultados podem ter sido influenciados pelo número reduzido de biópsias analisadas. 
ABSTRACT: The clinical and pathological variables are important factors that may be associated with tumor progression and consequently, the prognoses of the disease. The glutathione S-Transferases GSTM1, GSTT1 and GSTP1 are enzymes from the second phase II of biotransformation that work in the detoxificatin pathways of a wide range of exogen agents including the carcinogens. The GSTM1 GSTT1 and GSTP1 genes are polymorphic in humans and their variants have been related in some populations an increased neoplasia risks, including colorectal cancer. In this retrospective study 50 biopsies of patients with colorectal carcinoma of South Brazilian were analyzed polymorphisms in the genes GSTM1, GSTT1 and GSTP1 by Multiplex PCR and RFLP for the clinical and pathological variables: location, stage and differentiation. There were no significant $p$ values for the variables: stage $(p=0,28, p=0,93$ e $p=0,67)$, differentiation $(p=0,70$ e $p=0,37)$ and location $(p=0,23$. $p=0,58$ e $p=0,60)$ respectively and the presence of polymorphism of GSTM1, GSTT1 and GSTP1 in variables staging and location. The only clinicopathological variable that showed significant value in the differentiation of CCR was the polymorphism GSTP1 ile/val and $\mathrm{val} / \mathrm{val}(\mathrm{p}=\mathbf{0 , 0 4 6})$, however, more research is needed to confirm these findings, since these results may have been influenced by the reduced number of biopsies analyzed.

Key words: GSTs, colorectal cancer, clinicopathological aspects.

\section{REFERÊNCIAS}

1- Ali-Osman, F., Akande, O., Antoun, G., Mao, J. X., and Buolamwini, J. Molecular cloning, characterization, and expression in Escherichia coli of full-length cDNAs of three human glutathione S-transferase Pi gene variants. Evidence for differential catalytic activity of the encoded proteins. J. Biol. Chem,1997; 272:10004-100012.

2- Astler VB, Coller FA. The prognostic significance of direct extension of carcinoma of the colon and rectum. Ann Surg1954;139:846-51.

3- Board P., Coggan M., Johnston P., Ross V., et al. Genetic heterogeneity of the human glutathione transferases a complex of gene families. Pharmacology and Therapeutics , 1990; 48: 357-369.

4- Bell DA, Taylor JA, Paulson DF, Robertson CN, et al. Genetic risk and carcinogenexposure: a common inherited defect of carcinogenmetabolism gene glutathione S-transferase Ml (GSTMl) that increases susceptibility to bladder cancer, J. Natl. Cancer Inst., 1993; 85:1159-1 164.

5- Bosman FT. Prognostic value of pathological characteristics of colorectal cancer. Eur J Cancer 1995;31:1216-21.

6- Brasil. Ministério da Saúde. Secretaria de Atenção à Saúde. Instituto Nacional de Câncer. TNM: classificação de tumores malignos / traduzido por Ana Lúcia Amaral Eisenberg. 6. ed. Rio de Janeiro: INCA, 2004. 254p.

7- Cain AS, Longino LA. Carcinoma of the colon in children. J Pediatr Surg.1970; 5:527-32.

8- Chapuis PH, Dixon MF, Fielding L P. Gordon PH, Hermanek P, Kyriakos M, et al. Staging of colorectal cancer. Symposium.Int J ColorectDis 1987;2:123-38.

9- Cotton SC, Sharp L, Little J, Brockton N. Human Genome Epidemiology (HuGE) Reviews - Glutathione S-transferase Polymorphisms and colorectal cancer: A HuGE Review. American Journal of Epidemiology, 2000; 51(1):7-32.
10- Doll R. The causes of cancers: Quantitative estimates of avoidable risks of cancers in the United States today, J. Natl. Cancer Inst, 1981; 66: 1191-1308.

11- Dukes C. The classification of cancer of the rectum. Journal of Pathology 1932;35:323-332.

12- Dukes CE. The classification of cancer of the rectum. J Pathol 1932;35:323-32. Michelassi F, Vanucci L, Ayala JJ, Chappel R, Goldrerg R, Block GE. Local recurrence after curative resection of colorectal adenocarcinoma. Surgery 1990;108:78793.

13- Garcia-Closas M, Malats N, Silverman D, Dosemeci M, et al. NAT2 slow acetylation, GSTM 1 null genotype, and risk of bladder cancer: results from the Spanish Bladder Cancer Study and meta-analyses. Lancet, 2005; 366:649-59.

14- Gaspar PA, Moreira J, Kvitko K, Torres MR, et al. CYP1A1,

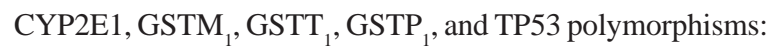
Do they indicate susceptibility to chronic obstructive pulmonary disease and non-small-cell lung cancer? Genet Mol Biol, 2004; 27:133-138.

15- Grinnel RS. The grading and prognosis of carcinoma of the colon and rectum. Ann Surg 1939;109:500-33.

16- Halvorsen TB, Sein E. Influence of mucinous components on survival in colorectal adenocarcinomas: a multivariate analysis.J Clin Pathol 1988;41:1068-72.

17- Harries LW, Stubbins MJ, Forman D, Howard G.C, et al. Identification of genetic polymorphisms at the glutathione Stransferase Pi locus and association with susceptibility to bladder, testicular and prostate cancer. Carcinogenesis, 1997; 18:641-644.

18- Hayes JD, Flanagan JU, Jowsey IR. Glutathione transferases. Annu Rev Pharmacol Toxicol, 2005; 45: 51-88.

19- Hermanek P, Guggenmoos-Holzmann I, Gall FP. Prognostic factors in rectal carcinoma. A contribution to the further development of tumor classification. Dis Colon Rectum 1989;32:593-9. 
20-Huttler RVP, Sobin L H. A universal staging system for cancer of the colon and rectum. Let there be light. Arch Pathol Lab Med 1986;110:367-8

21-INCA Instituto Nacional do Câncer Ministério da Saúde. (Brasil) http://www.inca.gov.br/ Estimativa/2008/ Acesso setembro de 2008.

22-Knudsen JB, Nilsson T, Sprechler M, Johansen A, Christensen $\mathrm{N}$. Venous and nerve invasion as prognostic factors in postoperative survival of patients with resectable cancer of the rectum. Dis Colon Rectum 1983;26:613-17

23-Kune GA, Kune S, Field B, White R, Brough W, Schellemberger $\mathrm{R}$, Watson LF. Survival in patients with large-bowel cancer. A population-based investigation from Melbourne Colorectal Cancer Study. Dis Colon Rectum 1990;33:938-46.

24-Lear J.Y., Heagerty A.H.M., Smith A., Bowers B., Payne C., Smith C.A.D., Jones P.W., Gilford J., Yengi L., Alldersea J., Fryer A., Strange R.C. Multiple cutaneous basal cell carcinomas: glutathione-S-tranferase $\left(\mathrm{GSTM}_{1}, \mathrm{GSTT}_{1}\right)$ and cytochrome P450 (CYP2D6, CYP1A1) polymorphisms influence tumour numbers and accrual. Carcinogenesis, 1996; 12: 1891-1896.

25-Martinez CAR, Priolli DG, Cardinalli IA, Piovesam H, Pereira JA. Importância da correlação entre o padrão de distribuição tecidual do antígeno carcinoembriônico e seus níveis séricos no prognóstico do câncer colorretal. Estudo prospectivo de 50 casos. Rev bras Coloproct 2004;24 (supl.1):90.

26-Michelassi F, Vanucci L, Ayala JJ, Chappel R, Goldrerg R, Block GE. Local recurrence after curative resection of colorectal adenocarcinoma. Surgery 1990;108:787-93.

27-Ministério da Saúde (BR). Secretaria de Atenção à Saúde. Instituto Nacional de Câncer. Coordenação de Prevalência e Vigilância. Estimativa 2005: incidência do câncer no Brasil. Rio de Janeiro (Brasil): INCA; 2004.

28- Miller PD, Liu G, De Vivo I, Lynch TJ, Wain JC, Su L and Christiani DC Combinationof the variant genotype of GSTP1, GSTM1 and, p53 are associated with an increased lung cancer risk. Cancer Res, 2002; 62:2819-2823.

29- Naylor EW, Lebenthal E. Gardner's syndrome; recent development in research and management. Dig Dis Sci 1980;25:945-59.

30- Nazarian HK, Giuliano AE, Hiatt JR. Colorectal carcinoma: analysis of management in two medical eras. J Surg Oncol 1993;52:46-9.

31- Neves FJ, Mattos IE, Koifman RJ. Mortalidade por câncer de cólon e reto nas capitais brasileiras no período 1980-1977. Arq Gastroenterol 2005; 42: 63-70. Rich T, Gunderson LL, Lew R, Galdibini JJ, Cohen AM, Donaldson G. Patterns of recurrence of rectal cancer afterpotentially curative surgery. Cancer 1983; 52:1317-29.

32- Norppa H.Genetic susceptibility, biomarkers response, and cancer. Mutat Res, 2003; 544:339-348.

33- Pemble S.E., Schroeder K., Spencer S., Meyer D., Hallier. Human glutathione S-Transferase Theta $\left(\mathrm{GSTT}_{1}\right)$ : cDNA cloning and the characterization of a genetic polymorphism. Biochem. J. 1994; 300, 271-276.

34- Perera FP and Weinstein IB. Molecular epidemiology: Recent advances and future directions. Carcinogenesis, 2000; 21:517524.

35- Phillips RK, Hittinger R, Blesowsky L, Fry JS, Fielding LP. Large bowel cancer: surgical pathology and its relationship to survival. Br J Surg 1984;71:604-10.

36- Ponz de Leon M, Antonioli A, Ascari A, Zanghieri G. Sacchetti C. Incidence and familial occurrence of colorectal cancer and polypsin a health-care district of Northern Italy. Cancer 1988;62:2858-9.

37- Rich T, Gunderson LL, Lew R, Galdibini JJ, Cohen AM, Donaldson G. Patterns of recurrence of rectal cancer after potentially curative surgery. Cancer 1983; 52:1317-29.

38- Sanfelippo PM, Beahrs OH. Factors in the prognosis of adenocarcinoma of the colon and rectum. Arch Surg 1972;104:401-6.

39- Sariego J, Byrd ME,Kerstein M, Sano C, Matsumoto T. Changing patterns in colorectal carcinoma: a 25 years experience. Amsurg 1992;58:686-91.

40- Thebo JS, Senagore AJ, Reinhold DS, Stapleton SR. Molecular staging of colorectal cancer. Dis Colon Rectum 2000;43:15562.

41- Watson MA, Stewart RK, Smith GB, Massey TE, et al. Human glutathione S-transferase P1 polymorphisms: relationship to lung tissue enzyme activity and population frequency distribution. Carcinogenesis, 1998; 19: 275-80.

42- Wilkinson J., Clapper M. L. Detoxification enzymes and chemoprevention. Proceeding Society Experimental Biological Medicine, 1997; 216: 192-200.

43- Williams NS, Durdey P, Johnston D. The outcome following sphincter saving resection and abdomino-perineal resection for low rectal cancer. British Journal of Surgery 1985;72:595598.

44- Wolmark N, Wieand HS, Rockette HE, Fischer B, Glass A, Lawrence W, Lerner N, Cruz AB, Volk H, Shibata H, Evans J, Prager D. The prognostic significance of tumor location and bowel obstruction in Dukes B and C colorectal cancer. Findings from the NSABP clinical trials 1983;198:743-52.

45- Zinkin LD. A critical review of the classifications and staging of colorectal cancer. Diseases of the Colon and Rectum 1983;26:37-43.

\section{Endereço para correspondência:}

POLIANA L. ANSOLIN

Rua Osório Mendes Ouriques, 332 - Casa 4

Guarujá - Porto Alegre - RS

CEP: 91770-003

E-mail:polibio@yahoo.com.br 